\title{
Do Campaigns Really Change Behavior?
}

\author{
New Understanding of the Behavioral Effects of \\ Advertising, Political Campaigns \\ and Health Communication Campaigns
}

\author{
Magne $\mathrm{HaUG}^{1}$
}

The American social psychologist William McGuire claimed in an influential article ("The myth of massive media impact" (McGuire 1986)) that although the mass media has important influences on the way we live and think, mass-media persuasion, i.e. deliberate efforts to influence the way we think or behave, has small or nonexistent documented effects. This article asserts that McGuire was too pessimistic. For a number of years, media researchers found it difficult to document large effects of mass-media persuasion on behavior. This is, however, no longer the case. This article gathers recent research on advertising, political campaigns and health campaigns that show it is now possible to document relatively large effects of media campaigns on behavior. Some research also shows how and when these effects may be attained. The focus is on behavior, rather than intermediate variables like beliefs or attitudes; on intentionally persuasive campaigns, rather than direct or indirect effects of media coverage; on the persuasion of adults, rather than children. Issues for further research are also discussed.

The mass media are so pervasive in our daily life, so integrated into the way we live, so essential for what we know about society and our environment that it seems unreasonable to even doubt that it affects us. The worlds of government, politics and business are built on the assumption that we use the media to get informed on what is happening around us, outside the narrow perimeter of what we are able to see with our own eyes or learn through conversation at any moment (McQuail 2000: 416). Among campaign implementers in the advertising industry and political consultants, it has long been obvious that massmedia campaigns have effects large enough for investments in campaigns to be profitable.

The issue of effects of persuasive campaigns has, however, been contested by social scientists who have met with serious difficulty in actually documenting effects through research. The conflicting conclusions - campaign workers insisting on the existence of effects, social scientists doubting it - may be seen as the classic conflict between knowledge and understanding, or between practical and scientific - or real - knowledge (Aristotle 1979). We sometimes think we know something based on our practical experience, but are proven wrong, after closer scientific scrutiny. To many social scientists, this seemed to be the case with mass-media persuasion. Over the decades, many media researchers seem to have accepted the thesis from the 1940s, expressed in an influential book from 1960 as the mass media not seeming to have much effect on actual behavior 
(Klapper 1960). In the 1970s and 1980s this conclusion was modified through research on agenda setting, uses and gratification, cultivation effects, knowledge gap effects and media priming. According to this research, media use has a set of important and influential effects on audiences. But may these effects be deliberately summoned at the will of a mass-media campaign manager? William McGuire, one of the world's leading social psychologists, concluded as late as 1986 that there is little evidence of mass-media persuasion having any effect on receiver attitudes, beliefs or actions (McGuire 1986; Shrum 2002). The crucial point made by McGuire was that the media may influence the way society works, how we interact and where we get our information to perform our daily duties, but there is little evidence that mass-media messages can persuade people to hold a specific belief or attitude, or perform a concrete behavior in a specified setting over an ascertained period of time.

This was seen to be the case for political election campaigns as well as health campaigns and commercial advertising. Political scientists had difficulty certifying that the mass-media campaign actually changed voter behaviors. For a number of years it was found that for elections in the United States you could predict election outcomes by voter attitudes six months before elections, well before the campaigns got off the ground (Holbrook 1996). Studies on advertising held that its proven influence on consumers was minimal, a conclusion that even caused buyers of advertising to switch from advertising to promotional activities in the late 1980s (Turk and Katz 1992; Vakratsas and Ambler 1999; Jones 2002).

The problem may be methodological. Media consumption is so pervasive in our daily life that it is difficult to study its effects. It is difficult to find segments in which the media does not play an important role. It is difficult to separate the media's effects on our behavior from all other effects from our integration in society. Consequently, the lack of evidence of such effects does not necessarily imply that they do not exist, but may instead be a consequence of how we measure effects. As Rogers has pointed out, when you study limited interventions of a clearly defined period of time, you often find strong effects of the mass media on behavior (Rogers 2002). There are, thus, good reasons to review the campaign research literature to see whether the pessimistic attitude regarding campaign effects reported by McGuire in 1986 and confirmed by Shrum in 2002 hold up in the light of recent campaign research.

\section{Method}

In studying campaign effects, I will review the campaign effects literature beginning in the early 1980s. This is a surprisingly easy task, as such literature is limited. I will review literature in the three main fields of study in which campaigns are designed to influence behavior:

1. Political campaigns that influence two sorts of voting behavior - whether people vote and whom they vote for.

2. Advertising or commercial campaigns that influence consumer behavior.

3. Health campaigns that influence health behavior.

Within these three fields, I have conducted an extensive literature search of the communication, advertising and political science research literature to find books and articles in scientific journals that study behavioral effects of campaigns. I have also included literature reviews and meta-analyses found in the health communication literature. 
This article looks at behavior, not at intermediate variables like beliefs or attitudes. Most media persuasion studies, on the other hand, have been interested in intermediate variables as it is easier to measure the influence of a message on beliefs and attitudes than on behavior. Behavior is sometimes not even considered a relevant dependent advertising variable (Thorson 1989). The focus in this article is also on intentionally persuasive campaigns, rather than on direct or indirect effects of media coverage ${ }^{2}$.

The behaviors relevant to the three fields of study - political, commercial and health - are very different in nature, thus I will discuss them separately.

- Political campaigns try to influence a one-time behavior - voting on polling day. For the voter this behavior has no short-term benefit, and may or may not have a long-term benefit which always is difficult for the voter to know, - when s/he votes or later. In studies on political voting the focus is often on two different aspects of the same act: 1 . Whether the votes actually votes, and 2 . who s7he votes for. Although most persuasion is done regarding parties or candidates, voting research has often been focused on whether or not people.

- Commercial advertising tries to influence one-time behaviors in a perspective of repetition. Ads are more successful the more they can make customers repeat the desired behavior. Commercial advertising is usually, though not exclusively, concerned with convincing the customer that particular product or service will serve his/her needs.

- Health campaigns are very different from commercial campaigns as they often attempt to make people abstain from things they like to do, such as smoking or driving when drunk (Slater and Flora 1994). It does not make it easier that these behaviors may be habits that are reinforced through interaction with friends or family (Slater and Flora 1994). Health campaigns sometimes also attemtps to make people do something they do not want to do, like using a condom while having sex. People's experience is that the greater short-term benefit is derived from not doing it, while the campaign tries to convince them of the long-term benefit of doing it. Similar to ad campaigns, but different from political campaigns, health campaigns usually focus on repeated behavior as much as on one-time behavior.

The mass media is only one of several channels of communication. It is integrated into a network of social relationships, personal relations, and job relations, all of which can be used to reach us with persuasive intent. When the mass media stimulate interpersonal communication about a given topic the effects of direct exposure to media messages are often magnified (Rogers 2002). Mass media interacting with interpersonal communication give the best effect on behavior in campaigns (Atkin 2001). In this article I will look at just what the mass-media component of this interaction seems to contribute.

\section{Results}

Findings from the three areas of study are presented separately and then discussed together at the end of the article.

\section{Behavioral Effects of Political Campaigns}

Political advertising is increasingly the main element in political campaigns, rendering party machines and grass-root organizations less important than they were in the past (Iyengar and Simon 2000). In the US, political advertising has traditionally been re- 
searched in terms of its influence on four classes of dependent variables: attention, knowledge, attitudes toward ad sponsors or their opponents, and likelihood of voting (Leshner, Holbert et al. 2002). Actual voting behavior has not been used to a large extent as a measure of political campaign effects or effectiveness.

Until the late 1990s, it was commonly accepted among political campaign researchers that McGuire was right in claiming that political media campaigns seemed to have little effect. Campaigns seemed mostly to confirm already existing attitude and voting intentions. This conclusion is the more surprising when one considers that in 2000, political candidates in the US spent a total of more than a billion dollars on the election. This amount has steadily increased. This conclusion also contradicts the weekly swings in party or candidate support, observable to everyone. These are real swings, even considering the uncertainties in published numbers. The swings seem to be connected to political initiatives by the candidates, for instance when German Chancellor Gerhard Schroeder in the fall 2002 German national elections turned a seemingly losing situation into a narrow win after playing the "anti-war-in-Iraq" card in the election campaign's final weeks. Political campaign consultants build their profession on a belief that political coverage and political advertising are measures that exerts strong effects on voters. Political consultants use opinion polling to select messages to influence voters. Opinion polling is used not only to select the issues to focus on in political advertising, but also in political initiatives and speeches (for an example, see Morris 1999). This procedure is much criticized by political scientists and political commentators, but is defended by consultants who claim the polling is not used to decide which opinion the politician should have, but instead only to select which of the candidate's opinions are to be focused on in his/her public performances and in his/her political advertising (Newman 1999: 16). Do politicians and their support teams not know what they are doing, or have social scientists made serious mistakes in not seeing what those involved in campaigns saw?

In recent years there has been a new understanding of the importance of campaign communication for elections. In a study of the 1984, 1988 and 1992 US presidential elections, Holbrook argues that campaigns did have an influence. He concluded that "variations in candidate support during the campaign season are largely attributable to the occurrence of campaign events". (Holbrook 1996: 154) National conditions, usually ascribed the main influence on election outcomes, varied little under the campaign and consequently had little influence on variations in public opinions during the campaign. He did find, though, that in spite of the large variations in public opinion during the campaign, on Election Day voters did tend to bring about the outcome initially predicted based on national conditions (Holbrook 1996).

Zaller has developed a possible explanation for why the result may turn out as originally predicted, although the campaign still has an influence on what happens. He claims that "at least in the domain of political communication, the true magnitude of the persuasive effect of mass communication is closer to 'massive' than to 'small or negligible' and that the frequency of such effects is "often"'. (Zaller 1996: 19) Zaller sees the lack of effects as a methodological artifact. The impression of no effects is connected to (at least) two phenomena that are typical of election campaigns. First, that a continuous stream of coverage of political issues leads to "inadequate variation in the media inputs to mass opinions for ready detection of media effects, even if such effects are massively present" (Zaller 1996). To measure difference, there must be a difference. When everyone is strongly influenced by the media, there is no control group to measure the effect against, and the impression that there is no effect is misleading. 
A second cause of seemingly small effects of mass-media messages is that strong effects of messages from opposing candidates nullify each other so that a false impression of small or no total effect appears. When measuring effects as a linear connection between the number of messages sent and behavior change in the form of votes, or intention to vote, one loses sight of the effect of the competing candidate.

To test his hypothesis of massive media effects, Zaller tracked down datasets of elections in which message disseminations from opposing candidates were not overlapping, and found confirmation for a non-linear model that supposes large effects of messages from both candidates. Messages led to defections to the candidate not initially supported of between 0 and $70 \%$. The effects were the largest among voters who did not habitually pay a great deal of attention to news. Anecdotal evidence supporting Zaller's conclusion is the swing in US voter support for a party's presidential candidate directly after he has received endorsement from the party convention. This shift is often in the $10 \%$ range.

There are some weaknesses in Zaller's study. First, he does not really differentiate between usual press coverage and political advertising. Actually one of the studies included in his paper builds its measurement of campaign coverage on positive or negative media coverage of the candidate. It excludes political advertising, which does play an important role in American political campaigns. Second, he assumes that people are influenced by mass-media messages in proportion to the amount of messages they receive (Zaller 2000: 33). This is contrary to evidence from research on advertising that indicates that only a limited amount of advertising actually makes consumers buy the product advertised (Tellis, Chandy et al. 2000; Jones 2002). Advertising research has found that the best way to use research is to determine at an early stage which ads work, and discard those that do not work.

A literature review of studies on political campaigns' behavioral effects on voting behavior yielded very few studies ${ }^{3}$. Traditionally, political advertising has not been researched in terms of actual voting behavior (Leshner, Holbert et al. 2002). In one of the few studies, Wanat found a correlation of 0.56 between a candidate's share of the total advertising expenditure in a district, and the share of the total vote for the winning candidate (Wanat 1974). Palda found that a dollar spent on political advertising resulted in 0.33 additional votes for the candidate. This study showed, however, that expenditures other than political advertising gave double this gain in votes (Palda 1973). A study of the connection between voter defection (to another candidate or party) and advertising expenditure showed that more expenditure meant more defection, but the connection was small, although statistically significant (Joslyn 1981). Although these smaller studies show an effect of political advertising on behavior, Zaller found that they do not document the massive effects of the media on behavior.

These studies have not, however, received much attention among political campaign researchers. That is now changing. There is an increasing understanding that "conceptual and methodological advances" have shown that the social science community has been mistaken, as "campaigns do matter and can be pivotal". (Iyengar and Simon 2000) One important understanding is that research tools used in the past were not good enough for observing what actually happened (a problem that has also influenced our understanding of commercial campaigns, which will be discussed in a later section).

An important new understanding is how campaigns not only influence whether voters vote or whom they vote for, but also the criteria voters use in making these decisions. When campaign consultants use marketing research to determine which messages to send to voters, they base their advice on a voter tendency to attend selectively to only a few issues in 
a campaign. By setting the agenda for the campaign on issues in which the candidate has a comparative advantage with voters, thus priming the voter to think about the candidate's position when making the voting decision, the campaigner influences voter behavior (Iyengar and Simon 2000: 157). Whereas attempts by candidates to change voter's opinions are met with voter resistance - they would rather vote for a candidate who agrees with them than change their opinion under influence of arguments from candidates - it is far easier for candidates or political parties to change the agenda of the public debate. This change may have subtle persuasive effects on voter behavior that are equally powerful as if the votershad been persuaded to change their opinions, but the influence often goes unnoticed by the voter. In this 'resonance model' of campaigns, the effects are contingent on the degree of fit between campaign messages and prevailing (voter) attitudes (Iyengar and Simon 2000: 158). The influence of messages on voter perceptions and behavior is strongest among 'undecided' voters who have a weaker underlying identification with candidates or parties, but have nonetheless opinions on positions. These marginal voters do, when persuaded that the candidate or party agrees with their own priorities, change their voting and can decide elections (Ansolabehere and Iyengar 1994; Zaller 1996; Iyengar and Simon 2000: 159). According to these findings, the more effective strategy for winning elections is to determine what the voters want, and then design either the positions you take, or the positions you focus on in the campaign to be in harmony with those popular among voters. This is derogatorily called 'populism' by political commentators, but is the way elections have been won over the last decade by electoral stars like Tony Blair in the United Kingdom, Bill Clinton (Norris 2000) in the US, Gerhard Schroeder in Germany and Carl I. Hagen and Kristin Halvorsen in Norway. Not doing so is how French socialist presidential candidate Lionel Jospin lost the election and the other main candidate, Jacques Chirac, almost lost the election in 2002 as well as how the Norwegian Labor party lost almost onethird of its support between the 1997 and 2001 elections. The strategy may thus be called 'Let the voters decide'.

Political campaigns may also have indirect, unintended effects on voter behavior. Most attention has been given to negative campaign messages (derogatory messages about competitors in a campaign). The effects have been unclear, however. In some cases negative campaigns have been found to have negative effects on voter turnout, and at other times to stimulate voter turnout, notably when endorsements running counter to the view of the voter creates a third-person effect that increases his/her intention to vote (Leshner, Holbert et al. 2002).

\section{Behavioral Effects of Advertising or Commercial Campaigns}

Does advertising have behavioral effects? The entire advertising industry is built on the belief of an experience of behavioral effects. Why do academics doubt such effects, or claim that they exist if it is difficult to substantiate the claim? McGuire's conclusion was that both micro- and macro-strategies for evaluating the efficacy of commercial advertising in promoting sales fail to show the expected strong effects (McGuire 1986: 182). Some more recent literature reviews have confirmed this (Tellis 1994), while others have strongly disputed it. The fact is that there are few detailed studies on the behavioral effects of advertising (Tellis 1994). A set of case studies has shown strong short-term effects of campaigns on sales (Jones 2002). In a recent study, the buying of a service (use of the weight room in a training facility) increased to almost five times the initial use after an outdoor advertising campaign (Bhargava and Donthu 1999). In another study, exposure to printed store sale flyers led to a doubling of the number of advertised products 
bought, and more than a doubling of the amount spent on items in ads (Burton, Lichtenstein et al. 1999). Products with a larger share of sales used for advertising have been found to have a larger share of market and a higher return on investment (see also Kim 1992; Biel 1998). A literature review concludes that advertising elasticity range from 0 to 0.2 , implying that a $1 \%$ increase in advertising spending leads to a $0-20 \%$ increase in sales (Vakratsas and Ambler 1999). Ninety percent of advertising effects dissipate after three to fifteen months. The first response is most important; the share returns for advertising diminish fast. After the third exposure advertisers should focus on reach rather than frequency, according to research findings from advertising effects research (Vakratsas and Ambler 1999). A study of the connection between the brand that new (teenage) smokers select, and the advertising for cigarette brands found a correlation of 0.93 between advertising amount and brand selection (Pierce, Gilpin et al. 1991; Pucci and Siegel 1999). Biel found that reducing advertising during a recession does not pay. On the contrary, increasing advertising during a recession pays off in the form of a larger market share which, in turn, will give a higher return on investment once the recession is over (Biel 1998).

While some claim that advertising seems not to be important for sales in the short term, although more important in the longer term (Tellis 1994; see also Tellis, Chandy et al. 2000), others disagree. Jones found that advertisements must work in the short term to be able to have any medium or long-range effect on sales (Jones 2002).

The influence of advertising has been estimated to be $9 \%$ of the variation in sales for consumer products. The effect of promotional activities - such as offers of reduced prices for shorter periods of time - was more than double that size (Jones 2002). In some studies price reductions have been found to be 20 times more effective for increasing sales than is advertising (Tellis 1994), a consequence being that since the late 1980s the industry has changed its emphasis from advertising to promotion (Turk and Katz 1992; Vakratsas and Ambler 1999; Jones 2002). ${ }^{4}$

The solution to the problem of small effects may be that most advertising research has not taken into consideration the fact that only a small amount of advertising seems to increase sales. Increased spending on advertising (increased number of exposures and increased gross rating points) has been found to induce larger sales when ads were persuasive, but not when they were not (Stewart, Paulos et al. 2002). This is in accordance with a famous finding from the 1970s by the Campbell Soup Company that the amount spent on advertising did not influence its effect on sales, but copy strategy, media selection, media mix, and targeting did (Jeffres 1997: 251). The advertising copy and novelty in ads seemed more important than the amount of advertising itself (Tellis 1994). The two most important qualities of ads that sell products are likeability of the ad (Biel 1998) and its ability to make people believe that a company has an excellent product (Joyce 1998: 20). A study has shown that advertising likeability predicted sales winners $87 \%$ of the time (Biel 1998). It is no news that copy research works (Caples 1997; for a review, see Jeffres 1997: 252-263), but new data-processing techniques have made it possible to apply this knowledge almost instantly to TV advertising as well (Woodside 1996). Channel selection may also be an important influence on sales (Tellis, Chandy et al. 2000). For some groups of products (lower-priced daily consumer goods) the first exposure to advertising may contain most of the ad's effect on behavior (Jones 1995; Jones 2002).

In a series of studies of the effect of advertising on brand sales, Jones and his team found large effects of advertising for only $30 \%$ of consumer brands in the research, small for $40 \%$, and negative (decreased buying) for 30\% (Jones 2002). This last finding was 
not interpreted as advertising leading to a decline in buying per se, but rather a decline in buying of this advertised brand, preferring competing brands. They found an increase in buying of $20-140 \%$ over a period of seven days, with decreasing effects as time elapsed since the ad (Jones 1998: 87-8). These findings applied TV advertising; others have found a positive short-term effect of advertising on brand share only for newspaper ads, not for magazine or TV (Bogart 1998), while Jones found a medium-term effect of $60 \%$ from television advertising, 20\% from print and 10\% from radio (Jones 2002, computed from Table 6.3, page 99). ${ }^{5}$ One conclusion is that it important to use several different sources of advertising to receive the maximum marginal return on investment (Jones 2002: 112). ${ }^{6}$

The interesting new findings concern short- or medium-term effects. The important question for the users of advertising concerns long-term effects. If advertising has a longterm effect, it is easier for advertisers to live with small effects in the short term. In the 1980 s, research indicating that advertising has a much smaller short-term impact on sales than does promotion, led to a change in emphasis among marketers from advertising to promotion. What this change may have underestimated is the ability of advertising to increase its own effect with time. This is central to the concept of brand, indicating that a product is so well established in consumer consciousness that it may be preferred even with less advertising. Jones claims that the most important long-term effect of advertising that works is larger advertising elasticity. This means less advertising is needed to create the same sale (Jones 2002: 172f), which increases profitability of the brand. Less expense gives the same income. He has not documented this claim by research, however, and it has been contradicted in other research that found advertising elasticity to be dynamic and decrease during the product life cycle, which means elastcity is higher for new brands than for established brands (Vakratsas and Ambler 1999).

Jones discusses a pretesting procedure for television advertising with a correlation score of 0.70 between pretesting score for consumers intention to buy the product after seeing its advertising, and the actual sales of the product (Jones 2002: 48). This is an impressive connection, showing that once the message has been shown by pretesting to influence behavior, it actually does influence behavior on a large scale. This is interesting because advertising agencies, notably in Norway, have traditionally been skeptical of quantitative pretesting of advertising. They prefer qualitative pretesting that may provide something interesting and important information about consumer reactions to advertisements, but cannot provide reliable information about how advertisements will influence consumer behavior.

There is an interesting connection between low scores on the pretest and negative sales. If a brand is not advertised adequately, its sales will decline because consumers are exposed to competing advertising that will persuade them to buy other brands (Jones 2002: 47), a finding comparable to those of Zaller for election campaigns. But while Zaller supposed that all messages have effects, and changes in voting behavior are explained in one candidate sending more messages than the other, the advertising research underlines the importance of the persuasive quality of messages. When an unconvincing message competes with a convincing one for a different product, the product with the less convincing message loses. The same is likely to happen in election campaigns, and may explain why voters change their allegiance so often in modern, more intense media campaigns.

Competition between messages does not, however, explain all negative trends, notably in non-commercial advertising. Campaigns may have boomerang effects, which implies that they influence people to perform the opposite behavior of what they intended. 
In certain entertainment education campaigns, it was found that a subsection of the target group interpreted messages as confirmation of the attitudes and behaviors the campaign was designed to change (Rice and Atkin 1989; Singhal and Rogers 1989; see also Windahl, Signitzer et al. 1992; Singhal and Rogers 2001).

The variations in effects are connected to properties of the message, and to media planning schedules. It may take exposure for ads to "wear in", and to "wear out" (Stewart, Paulos et al. 2002). Hollis found both short-term and long-term effect of advertising on sales, and stronger effect of advertising on sales when the company had actual news about the product to present in its advertising (Hollis 1998). He claims that advertising influences sales through amplifying and reinforcing perceptions of already existing qualities in products.

But is advertising cost-effective? One of McGuire's main argument against advertising effectiveness was its lack of cost-effectiveness (McGuire 1986). Tellis found that even effective ads may not be profitable, and that profitable ads are rather few (Tellis, Chandy et al. 2000: 45), a finding confirmed by Jones, who claims that because of the lack of cost-effectiveness, advertising must be seen as an investment, such as production costs (Jones 2002). This is connected to how advertising interacts with price to influence buying behavior. The present conclusion of research seems to be that advertising makes buyers less price-sensitive, which means that as a consequence of advertising, producers may increase the price and consequently their profits, without a comparable reduction in sales. The exception to this rule is price advertising, which makes consumers more conscious about price and consequently seems to lead to a fall in price (for a discussion, see Vakratsas and Ambler 1999: 28-29).

\section{Behavioral Effects of Health Campaigns}

A standard impression of health campaigns has been that they have yielded disappointing results. Negative findings may, however, have received too much attention. One reason is measurement problems. A number of health campaigns have shown rather large effects, but it has not been possible to evaluate them because they were national campaigns, making control groups impossible (Hornik 2002). Another reason is campaigns designed to neutralize the effects of health campaigns. The possibly largest anti-smoking effort ever, the California anti-smoking campaigns, spent more than 500 million dollars between 1989 and 1996. The campaigns had a considerable effect on smoking prevalence between 1990 and 1993 before the tobacco industry through counter advertising and an extensive lobbying strategy, succeeded to emasculate the campaign (Pierce, Emery et al. 2002). Research indicates that the effect of the mass-media campaign was a main reason why tobacco industry lobbying focused on destroying the campaign (Pierce, Emery et al. 2002: 112).

A recent meta-analysis of 48 studies of the behavioral effect of mass-media health campaigns found that $9 \%$ more people performed the healthy behavior after the campaign than before (95\% confidence interval: 7\%, 10\%) (Snyder 2001; see also, Snyder and Hamilton 2002; Snyder, Hamilton et al. 2002). Campaigns with an enforcement component (like police ticketing seat-belt provision offenders) had an average change of behavior among $17 \%$ those exposed to the campaign, while for campaigns without enforcement, the effect was only 5\% (Snyder 2001). In an analysis of published data on all US health campaigns between 1980 and 1994, Freimuth and Taylor found that of 29 campaigns, 20 were successful in changing behavior and 9 were not. Median behavior change among campaigns evaluated using a rigorous experimental design model was 
29\% (range: $4 \%$ to $74 \%$ ) (Freimuth 1995). The size of influence on behavior found by Jones for brand advertising (9\%), and by Snyder and Hamilton for public mass-mediated health campaigns $(9 \%)$, is comparable to the effect size found in family planning programs around the world (8\%t) (Bauman 1997), in school smoking interventions (5\%) (Rooney and Murray 1996) and in school anti-drug programs (6-8\%) (Snyder and Hamilton 2002: 375).

There is a snag, however. Snyder and Hamilton discuss short-range changes, up to a year. One study found an increasing effect of an anti-smoking campaign over four years, with an accumulated effect of $12 \%$ (Flynn, Worden et al. 1994). But some school and community studies have found no long-range effects of some very large and famous public communication campaigns on smoking (Murray, Hannan et al. 1994; COMMIT Research Group 1995; Peterson, Kealey et al. 2000), health behavior (Baranowski, Davis et al. 2000) and cardiovascular disease (Fortmann and Varady 2000).

The overall impression from health campaigns is that we still see too many cases in which massive mass-media campaigns do not work properly, and that we do not have a deep enough understanding of why this is the case.

\section{Discussion}

I have presented research indicating that McGuire was mistaken when he claimed in 1986 that there is no massive impacts resulting from mass-mediated persuasive campaigns. Recent research, based on better methodological tools and better conceptualization of the effect problem, has made it possible for social scientists to also see what had seemed obvious to campaign implementers. In political campaigns it has been possible to track down changes in opinions during the campaigns as a result of competing campaigns, although these competing campaigns often neutralize each other to some extent creating the impression of campaigns having no effect. In advertising, point-of-sales technology has made it possible to closely track how advertising campaigns trigger sales, and to sort out the influence of advertising from other promotional activity. In health campaigns, recent development in the use of theory in campaigns seems to have created some that work, but this still seems to be the less effective campaign field.

There are two important lessons to be learned from the research reviewed. One is that serious methodological problems connected to measuring the effects of media persuasion may be closer to being solved. Through using more powerful data processing tools it has been possible to build more powerful models that can tell us when and why media persuasion works. This is in accordance with the broader development in media effect research. Since the 1960s, we have learned not to ask whether the media has effects on its public, but rather how the media influences its public.

The other lesson concerns the conditions under which mass-media persuasion may have effects. We have learned the importance of research - of message and channel testing - to detect when mediated messages have effects. We have learned the importance of good theoretical models detecting when and where media persuasion may work. If a message that does not work is used, no amount of money spent spreading it will make it work better. If campaign designers spend money wisely on research, as well as on developing messages according to their findings, mass-media persuasion may have powerful effects on target publics.

There are aspects of the issues I have not discussed. Campaigns benefit from the effects of both campaign messages and ordinary mass-media coverage of the same issues. 
It is not always possible to distinguish between the two, and this is more true as massmedia coverage generated through public relations about campaign issues is often an integrated part of the campaign. Campaign planners want "free" coverage of their issues. Some studies have found that $50-70 \%$ per cent of press coverage of political issues was instigated by sources that used the press to get their version to the public (Baerns 1985; Turk 1986; Baerns 1987). I have not taken up a discussion of the distinction, and it is not easy to do so. Further study is needed to be able to see these differences.

Implicit in my discussion was a one-way conception of the relationship between a medium and its audiences. The medium defines the situation through sending messages that the audiences receive. The important independent variables were seen as in the medium, not in the receiver. But are these conceptions correct, i.e. do they mirror the true relationship between medium and audience? In uses and gratification theory, the focus is on how audiences use the medium. This is also relevant for campaigns. To what extent, and how, does the individual receiver use the medium to gratify his/her own needs for knowledge, for ideas of what and where and when to buy, for entertainment? The extent and content of a receiver being influenced by a mass-media message, and notably a commercial message through advertising, is influenced by his/her own needs for information (Stewart, Paulos et al. 2002). These are issues complicating the study of persuasive effects of mass-media campaigns.

\section{Notes}

1. Magne Haug, Ph.D., is Associate Professor in the Department of Marketing, Norwegian School of Management BI, Oslo, Norway. Correspondence to: magne.haug@bi.no

2. I do not go into the nuances of when it is an effect of ordinary mass-media coverage or of deliberately designed messages, for instance advertising. It is not possible to make a total separation, as mass-media coverage is often an integrated part of campaigns. If campaign planners can get "free" coverage of their issues, and the coverage has an angle consistent with campaign objectives, campaign planners are happy. This can be achieved by deliberately leaking information to the press. Some studies have found that $50 \%$ or even $70 \%$ of press coverage of political issues was instigated by sources using the press to get their version through (Baerns, B. (1985). Öffentlichkeitsarbeit oder journalismus? zum Einfluß im mediensystem. Köln, Verlag Wissenschaft und Politik., Turk, J. v. S. (1986). "Information subsidies and media content: A study of public relations influence on the news." Journalism Monographs 100., Baerns, B. (1987). Journalism versus public relations: Determination of latent interaction through analysis of patterns of influence. Political communication research. D. L. Paletz. Norwood, Ablex: 88107.).

3. Thanks to Juyan Zhang, Monmouth University, for help in tracking down studies used in this section of the paper.

4. The problem with promotion is, however, that it may increase sales, but decrease average price and consequently profits. The effects of promotion also tend to disappear when the promotion stops, while advertising may have long-term effects, sometimes effects that do not seem to decrease over time.

5. Measured by return on investment, radio seems to be more effective than print, which in turn is more effective than TV, but this is an example of diminished returns on investment. Radio is effective because it is used infrequently. The more a medium is used, the smaller the marginal return on investment.

6. A general note on method regarding the Jones study: He gives almost all his numbers as absolute numbers, without computing the statistical uncertainty. This may at times cause him to draw conclusions about differences that may not be real, but may instead be caused by random errors in the data. 


\section{References}

Ansolabehere, S. \& Iyengar, S. (1994) "Riding the Wave and Claiming Ownership Over Issues. The Joint Effects of Advertising and News Coverage in Campaigns". Public Opinion Quarterly 58, pp. 335-357.

Aristotle (1979) Metaphysics. Grinnell, Iowa: The Peripatetic Press.

Atkin, C.K. (2001) Theory and Principles of Media Health Campaigns, in Rice, R.E. \& Atkin, C.K.: Public Communication Campaigns. Third edition. Thousand Oaks: Sage, pp. 49-68.

Baerns, B. (1985) Öffentlichkeitsarbeit oder journalismus? zum Einfluß im mediensystem. Köln: Verlag Wissenschaft und Politik.

Baerns, B. (1987) Journalism Versus Public Relations: Determination of Latent Interaction through Analysis of Patterns of Influence, in Paletz, D.L.: Political Communication Research. Norwood, Ablex, pp. 88107.

Baranowski, T., Davis, M. et al. (2000) "Gimme 5 fruit, Juice, and Vegetables for Fun and Health. Outcome evaluation”. Health Education \& Behavior 27(1), pp. 96-111.

Bauman, K.E. (1997) "The Effectiveness of Family Planning Programs Evaluated with True Experimental Designs." American Journal of Public Health 87(4), pp. 666-669.

Bhargava, M. \& Donthu, N. (1999) "Sales Response to Outdoor Advertising”. Journal of Advertising Research 39 (July/ August), pp. 7-18.

Biel, A.L. (1998) Likeability. Why Advertising that is Well Liked Sells Well, in Jones, J.P.: How Advertising Works: The Role of Research. Thousand Oaks: Sage, pp. 111-120.

Biel, A. L. (1998) Reduced Advertising and Its Impact on Profitability and Market Share in a Recession, in Jones, J.P.: How Advertising Works: The Role of Research. Thousand Oaks: Sage, pp. 297-307.

Bogart, L. (1998) The Turbulent Depths of Marketing, in Jones, J.P.: How Advertising Works: The Role of Research. Thousand Oaks: Sage, pp. 26-48.

Burton, S., Lichtenstein, D.R. et al. (1999) "Exposure to Sales Flyers and Increased Purchases in Retail Supermarkets". Journal of Advertising Research 39 (September/ October), pp. 7-14.

Caples, J. (1997) Tested Advertising Methods. Paramus, NJ: Prentice Hall.

COMMIT Research Group (1995) "Community Intervention Trial for Smoking Cessation: II. Changes in Adult Cigarette Smoking Prevalence”. American Journal of Public Health 85(2), pp. 193-200.

Flynn, B.S., Worden, J.K. et al. (1994) "Mass Media and School Interventions for Cigarette Smoking Prevention: Effects 2 Years after Completion”. American Journal of Public Health 84(7, July), pp. 1148-1150.

Fortmann, S.P. \& Varady, A.N. (2000) "Effects of a Community-wide Health Education Program on Cardiovascular Disease Morbidity and Mortality. The Stanford Five-city Project". American Journal of Epidemiology 152(4), pp. 316-323.

Freimuth, V. (1995) Are Mass Mediated Health Campaigns Effective? A Review of the Empirical Evidence.

Holbrook, T.M. (1996) Do Campaigns Matter? Thousand Oaks: Sage.

Hollis, N.S. (1998) Television Advertising: Measuring Short- and Long-term Effects, in Jones, J.P. How Advertising Works: The Role of Research. Thousand Oaks: Sage, pp. 244-265.

Hornik, R.C. (2002) Public Health Communication: Making Sense of Contradictory Evidence, in Hornik, R.C.: Public Health Communication. Evidence for Behavior Change. Mahwah, New Jersey: Lawrence Erlbaum Associates, pp. 1-22.

Iyengar, S. \& Simon, A.F. (2000) "New Perspectives and Evidence on Political Communication and Campaign Effects." Annual Review of Psychology (51), pp. 149-169.

Jeffres, L.W. (1997) Mass Media Effects. Second Edition. Prospect Heights, Illinois: Waveland Press.

Jones, J.P. (1995) "Single-source Research Begins to Fulfill its promise." Journal of Advertising Research 35(May/June), pp. 9-16.

Jones, J.P. (1998) Is Advertising Still Salesmanship? in Jones, J.P.: How Advertising Works: The Role of Research. Thousand Oaks: Sage, pp. 82-94.

Jones, J.P. (2002) The Ultimate Secrets of Advertising. Thousand Oaks: Sage.

Joslyn, R.A. (1981) "The Impact of Campaign Spot Advertising on Voting Defection." Human Communication Research 7(4), pp. 347-360.

Joyce, T. (1998) The Advertising Process, in Jones, J.P.: How Advertising Works: The Role of Research. Thousand Oaks: Sage, pp. 11-25.

Kim, P. (1992) "Does Advertising Work: A Review of Evidence.” Journal of Consumer Marketing 9(4), pp. 5-21.

Klapper, J.T. (1960) The Effects of Mass Communication. Glencoe, Illinois: The Free Press. 
Leshner, G., Holbert, R.L. et al. (2002) Motivating Turnout: Counter-endorsement Third-person Effects, Campaign Negativity, and Voting. Paper presented to the Mass Communication \& Society Division of AEJMC, annual conference, Miami, FL, August 2002.

McGuire, W.J. (1986) "The Myth of Massive Media Impact: Savagings and Salvagings." Public Communication and Behavior 1, pp. 173-257.

McQuail, D. (2000) McQuail's Mass Communication Theory. Fourth edition. London: Sage.

Morris, D. (1999) Behind the Oval Office. Los Angeles, Renaissance books.

Murray, D.M., Hannan, P.J. et al. (1994) "Assessing Intervention Effects in the Minnesota Heart Health Program". American Journal of Epidemiology 139(1): pp. 91-103.

Newman, B.I. (1999) The Mass Marketing of Politics. Democracy in an Age of Manufactured Images. Thousand Oaks: Sage.

Norris, P. (2000) A Virtuous Circle. Political Communications in Postindustrial Societies. Cambridge: Cambridge University Press.

Palda, K.S. (1973) "Does Advertising Influence Votes? An Analysis of the 1966 and 1970 Quebec Elections". Canadian Journal of Political Science VI(4), pp. 638-655.

Peterson, A.V., Kealey, K.A. et al. (2000) "Hutchinson Smoking Prevention Project: Long-term Randomized Trial in School-based Tobacco Use Prevention - Results on Smoking." Journal of the National Cancer Institute 92(24), pp. 1979-1991.

Pierce, J.M., Gilpin, E. et al. (1991) "Does Tobacco Advertising Target Young People to Start Smoking?" JAMA 266(22), pp. 3154-3158.

Pierce, J.P., Emery, S. et al. (2002) The California Tobacco Control Program: A Long-term Health Communication Project, in Hornik, R.: Public Health Communication. Evidence for Behavior Change. Mahwah, New Jersey, Lawrence Erlbaum, pp. 97-114.

Pucci, L.G. \& Siegel, M. (1999) "Exposure to Brand-Specific Cigarette Advertising in Magazines and Its Impact on Youth Smoking”. Preventive Medicine 29, pp. 313-320.

Rice, R.E. \& Atkin, C.K. (Eds.) (1989) Public Communication Campaigns. Second edition. Newbury Park: Sage.

Rogers, E.M. (2002) Intermedia Processes and Powerful Media Effects, in Bryant, J. \& Zillmann, D.: Media Effects. Advances in Theory and Research. Second Edition. Mahwah, New Jersey: Lawrence Erlbaum Associates, pp. 199-214.

Rooney, B.L. \& Murray, D.M. (1996) “A Meta-analysis of Smoking Prevention Programs after Adjustment for Errors in the Unit of Analysis". Health Education Quarterly 23(1), pp. 48-64.

Shrum, L.J. (2002) Media Consumption and Perceptions of Social Reality: Effects and Underlying Reality, in Bryant, J. \& Zillmann, D. Media Effects. Advances in Theory and Research. Second Edition. Mahwah, New Jersey: Lawrence Erlbaum Associates, pp. 69-96.

Singhal, A. \& Rogers, E.M. (1989) Pro-social Television for Development in India, in Rice, R.E. \& Atkin, C.K.: Public Communication Campaigns. Second edition. Newbury Park, CA: Sage, pp. 331-350.

Singhal, A. \& Rogers, E.M. (2001) The Entertainment-education Strategy in Communication Campaigns, in Rice, R.E. \& Atkin, C.K.: Public Communication Campaigns. Third edition. Thousand Oaks: Sage, pp. 343-356.

Slater, M. \& J.A. Flora (1994) Is Health Behavior Consumer Behavior? Health Behavior Determinant, Audience Segmentation, and Designing Media Health Campaigns, in Clark, E.M., Brock, T.C. \& Stewart, D.W. Attention, Attitude and Affect in Response to Advertising. Hillsdale, New Jersey: Lawrence Erlbaum, pp. 273-285.

Snyder, L.B. (2001) How Effective are Mediated Health Campaigns? in Rice, R.E. \& Atkin, C.K. Public Communication Campaigns. Third edition. Thousand Oaks: Sage, pp. 181-190.

Snyder, L.B. \& Hamilton, M.A. (2002) A Meta-analysis of U.S. Health Campaign Effects on Behavior: Emphasize Enforcement, Exposure, and New Information, and Beware the Secular Trend, in Hornik, R.: Public Health Communication: Evidence for Behavior Change, pp. 357-384.

Snyder, L.B., Hamilton, M.A. et al. (2002) "A Meta-analysis of the Effect of Mediated Health Communication Campaigns on Behavior Change in the U.S".

Stewart, D.W., Paulos, P. et al. (2002) Media Influences on Marketing Communication, in Bryant, J. \& Zillmann, D. Media Effects. Advances in Theory and Research. Second edition. Mahwah, New Jersey: Lawrence Erlbaum Associates, pp. 353-397.

Tellis, G.J. (1994) Modeling the Effectiveness of Advertising in Contemporary Markets: Research Findings and Opportunities, in Stewart, D.W.. Attention, Attitude and Affect in Response to Advertising. Hillsdale, New Jersey: Lawrence Erlbaum, pp. 55-65. 
Tellis, G.J. (1994) Modeling the Effectiveness of Advertising in Contemporary Markets: Research Findings and Opportunities, in Clark, E.M., Brock, T.C. \& Stewart, D.W. Attention, Attitude and Affect in Response to Advertising. Hillsdale, New Jersey: Lawrence Erlbaum, pp. 55-65.

Tellis, G.J., Chandy, R.K. et al. (2000) "Which ad Works, When, Where, and How Often? Modeling The Effects of Direct Television Advertising". Journal of Marketing Research 37(1), pp. 32-46.

Thorson, E. (1989) Television Commercials as Mass Media Messages, in Bradac, J.J.: Message Effects in Communication Science. Newbury Park: Sage, pp. 195-230.

Turk, J. v. S. (1986) "Information Subsidies and Media Content: A Study of Public Relations Influence on the News". Journalism Monographs 100.

Turk, P.B. \& Katz, H. (1992) "Making Headlines: An Overview of Key Happenings in Media Planning, Buying, and Research from 1985-1991". Journal of Current Issues and Research in Advertising 14(2), pp. 19-34.

Vakratsas, D. \& Ambler, T. (1999) “How Advertising Works: What do we Really Know?” Journal of Marketing 63(January), pp. 26-43.

Wanat, J. (1974) "Political Broadcast Advertising and Primary Election Voting". Journal of Broadcasting 18(4), pp. 413-422.

Windahl, S., Signitzer, B. et al. (1992) Using Communication Theory. London: Sage.

Woodside, A.G. (1996) Measuring the Effectiveness of Image and Linkage Advertising. Westport, Connecticut: Quorum Books.

Zaller, J. (1996) The Myth of Massive Media Impact Revived: New Support for a Discredited Idea, in Mutz, D.C., Sniderman, P.M. \& Brody, R.A.: Political Persuasion and Attitude Change. Ann Arbor: The University of Michigan Press, pp. 17-78.

Zaller, J. (2000) The Statistical Power of Election Studies to Detect Media Exposure Effects in Presidential Campaigns. Paper prepared for the 2000 Annual Meeting of the American Political Science Association, Washington D.C. 